\title{
Article
}

\section{The Pupal Pigmentation Pattern and Pupal Development in the Species of Aphytis Howard (Hymenoptera: Aphelinidae)}

\author{
Zhuhong Wang ${ }^{1}$, Yu Si ${ }^{1}$, Hui Zhang ${ }^{1}{ }^{\oplus}$, Zhengli Zhang ${ }^{1}$, Andrew Polaszek ${ }^{2, *} \mathbb{C}$ and Jian Huang ${ }^{1, *}$ \\ 1 State Key Laboratory of Ecological Pest Control for Fujian and Taiwan Crops, \\ Fujian Agriculture and Forestry University, Fuzhou 350002, China; wzhuhong@126.com (Z.W.); \\ siyuxsh@sina.com (Y.S.); 2170203003@fafu.edu.cn (H.Z.); zhenglizzl@126.com (Z.Z.) \\ 2 Department of Life Sciences, Natural History Museum, Cromwell Road, London SW7 5BD, UK \\ * Correspondence: A.Polaszek@nhm.ac.uk (A.P.); jhuang1234@126.com (J.H.); Tel.: +44-(0)-207-942-5573 (A.P.); \\ $+86-13905007245$ (J.H.)
}

check for updates

Citation: Wang, Z.; Si, Y.; Zhang, H.; Zhang, Z.; Polaszek, A.; Huang, J. The Pupal Pigmentation Pattern and Pupal Development in the Species of Aphytis Howard (Hymenoptera: Aphelinidae). Insects 2021, 12, 399. https://doi.org/10.3390/insects12050399

Academic Editor: Barbara Conti

Received: 9 April 2021

Accepted: 24 April 2021

Published: 30 April 2021

Publisher's Note: MDPI stays neutral with regard to jurisdictional claims in published maps and institutional affiliations.

Copyright: (c) 2021 by the authors. Licensee MDPI, Basel, Switzerland. This article is an open access article distributed under the terms and conditions of the Creative Commons Attribution (CC BY) license (https:// creativecommons.org/licenses/by/ $4.0 /)$.
Simple Summary: Aphytis species (Hymenoptera: Aphelinidae) have been considered as the most important natural enemies in biological control of armoured scale insects (Hemiptera: Diaspididae). However, it is difficult to identify the species of the genus, particularly that of the A. lingnanensis group, based on adult morphological characters. Although the differences in pupal pigmentation of Aphytis species have been documented previously, they have not been much used as taxonomic characters for Aphytis species identification. In this study, we present four characteristic pigmentation patterns of Aphytis pupae, together with photographs, including the categories of: entirely yellow, partly dark brown, entirely or predominantly black, and partly black pupae. No significant intraspecific variation in pupal colour pattern was detected despite relatively high numbers of specimens examined, many from multiple, and different, origins. We summarize the present status of pupal pigmentation in the described species of Aphytis, according to the species groups, which could be used as an important supplementary diagnostic character for distinguishing species of Aphytis, especially closely-related species.

Abstract: Species identification of Aphytis on the basis of adult morphology is extremely difficult, especially in the A. lingnanensis group, with several cryptic species. Pupal pigmentation could be used as one of the taxonomic characters for Aphytis species, and in some instances, pupal pigmentation actually provided the first clue to the distinctness of cryptic Aphytis species. The present study investigated the full-grown larvae or younger pupae of Aphytis species, and pupal pigmentation and pupal development were observed and photographed. Four characteristic pigmentation patterns of Aphytis pupae were summarized including: entirely yellow, partly dark brown, entirely or predominantly black, and partly black. The species in the chilensis and mytilaspidis groups, and some unassigned species, generally have entirely, or predominantly and or partly black pupae. The species in the chrysomphali, funicularis, and proclia groups generally have the pupae entirely yellow. The species of the lingnanensis group have the pupae both entirely yellow, e.g., A. fisheri, and partly dark brown pupae, e.g., A. lingnanensis, A. holoxanthus and A. melinus. The pupae of Aphytis species in this study had a developmental duration of about $5-8$ days at $27 \pm 1{ }^{\circ} \mathrm{C}, 70 \pm 5 \% \mathrm{RH}$ and a photoperiod of 10L: 14D. It was found that the pupal skin was always melanized at the beginning stage, generally in the first day, among the pigmented pupae of Aphytis species. As development continued, the pigmentation became darker and the eye colour changed from pale red/brown to green. No significant intra-specific variation in pupal colour pattern was detected despite relatively high numbers of specimens examined, many from multiple, and different, origins. Overall, our study indicates that pupal pigmentation could be more helpful in species identification of Aphytis.

Keywords: Aphytis; pupal coloration; biocontrol agents 


\section{Introduction}

The species of Aphytis Howard (Hymenoptera: Aphelinidae) are among the most important ectoparasitoids of armoured scale insects (Hemiptera: Diaspididae), and many of them were utilized successfully in biological control projects of important armoured scale pests around the world. For instance, A. lingnanensis Compere from Guangdong, China in 1947 and A. melinus DeBach from India and Pakistan in 1956-1957 were introduced into California, USA against the California red scale, Aonidiella aurantii (Maskell); A. holoxanthus DeBach was introduced into Israel in 1956-1957 from Hong Kong, China against the Florida red scale, Chrysomphalus aonidum (L.), and A. yanonensis DeBach \& Rosen was introduced into Japan in 1980 from Sichuan, China against the arrowhead scale, Unaspis yanonensis (Kuwana) [1-3].

However, species identification of Aphytis is extremely difficult on the basis of adult morphology, especially in the A. lingnanensis group, with several cryptic species. This difficulty is due to their minute size (rarely exceeding one millimeter in length), the propodeal crenulae not easy to observe, and the relative scarcity of reliable distinguishing characters, as well as often unsatisfactory slide-mounted specimens without clearly visible characters $[1,4]$.

Taylor [5] was the first to notice differences in pupal pigmentation, the yellow pupae and the dark pupae, between the closely related species $A$. chrysomphali (Mercet) and what was probably A. holoxanthus. Pupal pigmentation was consequently used as one of the taxonomic characters for Aphytis species not readily separable using adult morphology [1,6-12]. In some instances, pupal pigmentation actually provided the first clue to the distinctness of cryptic Aphytis species. A. lingnanensis, for example, was first recognized as distinct from A. chrysomphali on the basis of this character [7]. In the A. lingnanensis group, A. fisheri DeBach, $A$. holoxanthus and $A$. melinus are considered sibling or near-sibling species, almost inseparable at the adult stage, but they are different in pupal pigmentation. The pupae of A. holoxanthus exhibit dark brown pigmentation on both the mesosomal sterna and the base of the metasomal sterna, those of A. melinus are pigmented only on the mesosomal sterna, whereas the pupae of $A$. fisheri are entirely yellow [1]. Yasnosh [13] provided a key for identification of the Aphytis species from the pupae and meconia (in the former USSR), and Prinsloo [14] gave a key to distinguishing the pupae of Aphytis parasitic on the California red scale on citrus in South Africa.

In southern China there is a major Aphytis parasitoid associated with the Florida red scale on citrus, which was mistakenly identified as A. chrysomphali for long time, and later was clarified as $A$. holoxanthus on the basis of the pupal pigmentation (the former with yellow pupa and the latter with partly dark brown pupa), as well as the characters of propodeal crenulae (the former belonging to A. chrysomphali group and the latter to A. lingnanensis group) and other adult characters $[3,15]$.

Therefore, the aim of this study is to observe and document the taxonomic characters of pupal pigmentation and pupal development, in order to provide information useful for the separation of Aphytis species. We are not aware of any between-species or species group diagnostic studies in other Aphelinidae, nor indeed any other Hymenoptera genera.

\section{Materials and Methods}

\subsection{Culture of Aphytis Pupae}

Several species of armoured scale insects were collected from citrus and ornamental plants in the fields. The full-grown larvae or younger pupae of Aphytis species were removed individually from parasitized scale insect hosts, and placed each in an individually numbered plastic box ( $3 \mathrm{~cm}$ in diameter, $1.5 \mathrm{~cm}$ high), in which a filter paper was placed. The boxes were put into a climatic chamber for pupa culture, under the controlled conditions at $27 \pm 1{ }^{\circ} \mathrm{C}, 70 \pm 5 \% \mathrm{RH}$ and a photoperiod of $10 \mathrm{~L}$ : $14 \mathrm{D}$. The pupal pigmentation and pupal development were observed and photographed daily, also adding a drop of water on the filter paper to maintain humidity. Pigmentation of mature, green-eyed pupae was recorded and compared for Aphytis species. Length of pupal development was measured 
from the time of larval pupation until the formation of the mature pupa, indicated by the change in eye pigment to green.

\subsection{Identification of Aphytis Species}

The body colour of Aphytis species after emergence was initially photographed, and the specimens were preserved in $100 \%$ ethanol. Later the adult Aphytis specimens were photographed for details of the propodeal crenulae and thoracic tergum, and slide-mounted for species identification following the method outlined by Noyes [4].

\subsection{Photography of Specimens}

Specimens were photographed with a DS-Ri2 camera (Nikon, Tokyo, Japan) attached to a Nikon SMZ18 microscope with NIS-Elements D software and a DSC-T900 camera (Sony, Tokyo, Japan). The slide-mounted specimens were photographed using the Nikon DS-Ri2 camera and the same software attached to a Nikon Ni microscope equipped with differential interference contrast.

\section{Results}

Four characteristic pigmentation patterns of Aphytis pupae were recorded in this study, including: 1 . entirely yellow; 2 . partly dark brown; 3 . entirely or predominantly black, and 4. partly black.

\subsection{Type 1, Entirely Yellow Pupa}

In this category, four Aphytis species with entirely yellow pupae were from the funicularis, chrysomphali, lingnanensis and proclia groups.

\subsubsection{Aphytis gordoni DeBach \& Rosen (funicularis Group)}

The pupa of $A$. gordoni is entirely yellow, with pupal development lasting 5 days (Figure 1).
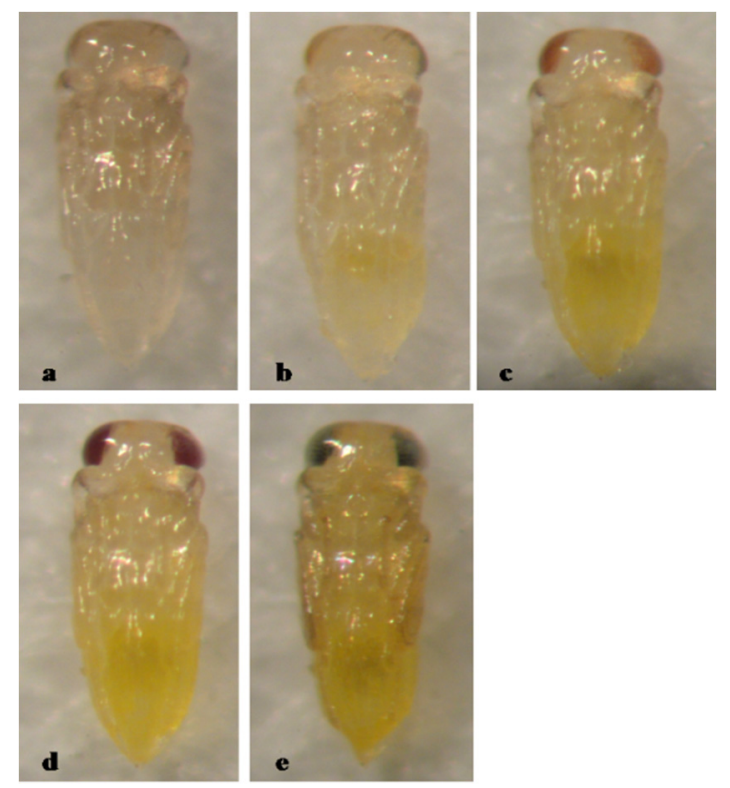

Figure 1. Aphytis gordoni DeBach \& Rosen. opupa, ventral view: (a) 1-day old, (b) 2-day old, (c) 3-day old, (d) 4-day old, and (e) 5-day old (mature).

Material examined. 19, ex Pinnaspis theae (Maskell) $o^{7}$ on tea. China: Fujian, Fuzhou, Jinshan, Fujian Agriculture and Forestry University (hereafter FAFU), tea plantation, 10.vi.2015, coll. Zhongchun Wen; 5, ex Pinnaspis theae o on tea. China: Fujian, Fuzhou, Jinshan, FAFU, tea plantation, 13-28.ix.2015, coll. Taishan Zhou; 19, ex an unidentified di- 
aspidid $0^{7}$ on bamboo, China: Fujian, Fuzhou, Jinshan, FAFU, 2.xi.2015, coll. Zhengli Zhang and Hui Zhang; $22^{\circ} 20^{\prime}$, ex an unidentified diaspidid $\sigma^{\prime}$ on Litchi chinensis Sonn. China: Fujian, Fuzhou, Jinshan, FAFU, 14.vi.2015, coll. Zhongchun Wen; 2ᄋ20 $20^{7}$, ex Aulacaspis yabunikkei Kuwana o on Cinnamomum camphora (L.) Presl. China: Fujian, Zhangzhou, 24.iv.2015, coll. Zhengli Zhang.

\subsubsection{Aphytis lepidosaphes Compere (chrysomphali Group)}

The pupa of A. lepidosaphes is entirely yellow, with pupal development lasting 7 days (Figure 2).
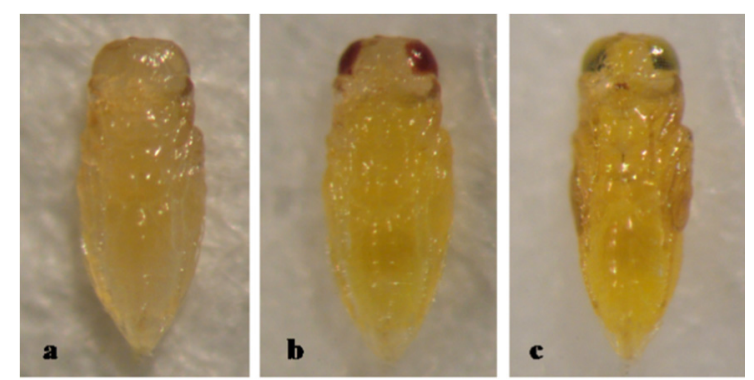

Figure 2. Aphytis lepidosaphes Compere. \&pupa, ventral view: (a) 1-day old, (b) 4-day old, and (c) 7-day old (mature).

Material examined. 4우, ex Cornuaspis beckii (Newman) on Murraya exotica L. China: Fujian, Fuzhou, Jinshan, FAFU, 14.xii.2014, coll. Xiurong Peng; 69, ex Cornuaspis beckii (Newman) on Ficus microcarpa L., China: Fujian, Fuzhou, Jinshan, FAFU, 15.xii.2014, coll. Zhengli Zhang.

\subsubsection{Aphytis fisheri DeBach (lingnanensis Group)}

The pupa of $A$. fisheri is entirely yellow, with pupal development lasting 5 days (Figure 3).

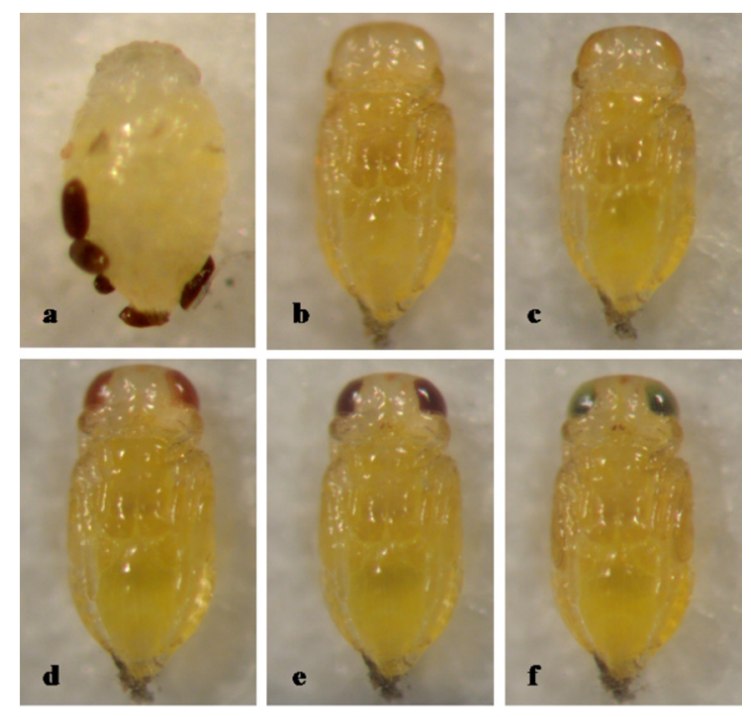

Figure 3. Aphytis fisheri DeBach. (a) a prepupa and meconia, \&pupa, ventral view: (b) 1-day old, (c) 2-day old, (d) 3-day old, (e) 4-day old, and (f) 5-day old (mature).

Material examined. $2920^{7}$, ex an unidentified diaspidid on Dianella ensifolia (L.). China: Fujian, Fuzhou, Jinshan, FAFU, 17.iv., 5.v.2015, coll. Yu Si and Zhongchun Wen; 19, ex Aonidiella citrina (Coquillett) on citrus. China: Fujian, Jian'ou, 4.xi.2015, coll. Xu Cai; 2920", ex an unidentified diaspidid on grass, China: Fujian, Fuzhou, 11.vi.2015, coll. Yu Si; 1, 
ex an unidentified diaspidid on Ficus microcarpa L. China: Fujian, Fuzhou, Jinshan, FAFU, 15.xii.2014, coll. Zhengli Zhang; 19, ex Pseudaulacaspis cockerelli (Cooley) on Michelia alba DC. China: Fujian, Xiamen, 31.i.2015, coll. Jian Huang and Hui Zhang.

\subsubsection{Aphytis hispanicus (Mercet) (proclia Group)}

The pupa of A. hispanicus is actually entirely yellow. The melanization seen in the late stage of pupal development (Figure $4 \mathrm{e}-\mathrm{g}$ ) is that of the developing adult, evident through the integument of the fully developed pupa. The pupal development duration is 7 days (Figure 4).

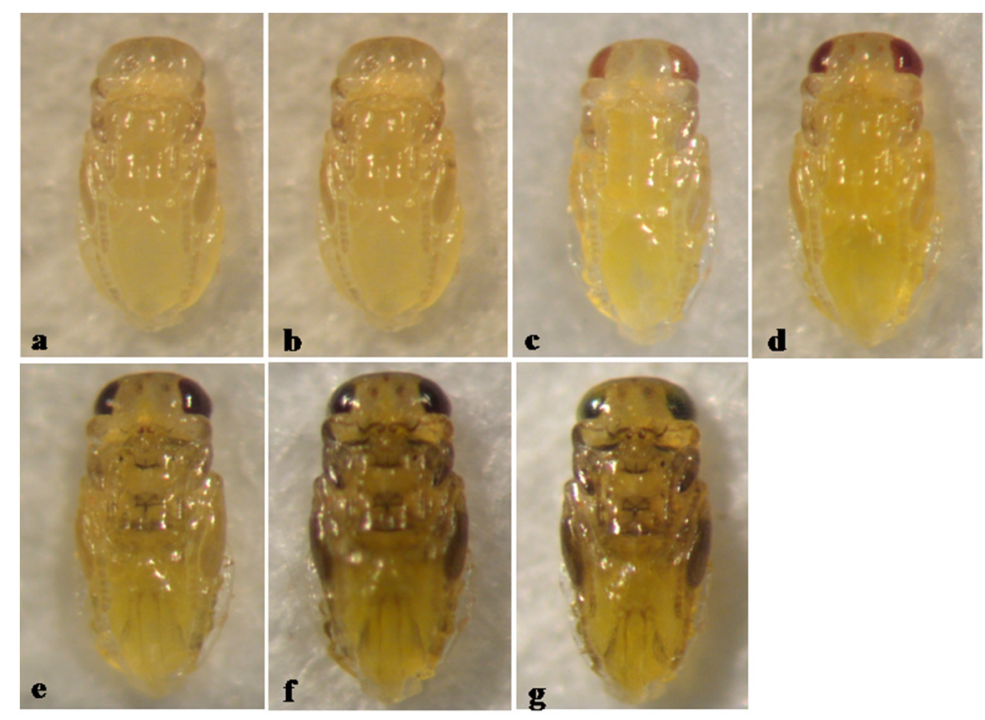

Figure 4. Aphytis hispanicus (Mercet). ๆpupa, ventral view: (a) 1-day old, (b) 2-day old, (c) 3-day old, (d) 4-day old, (e) 5-day old, (f) 6-day old, and (g) 7-day old (mature).

Material examined. 4ㅇ, ex an unidentified diaspidid on Ilex chinensis Sims. China: Fujian, Xiamen, 31.i.2015, coll. Jian Huang and Hui Zhang; 4우웅 ex Pseudaulacaspis cockerelli (Cooley) on Michelia figo (Lour.) Spreng. China: Fujian, Fuzhou, Jinshan, FAFU, 10.ii.2015, Xiurong Peng.

\subsection{Type 2, Partly Dark Brown Pupa}

In this type, the Aphytis species observed were characterized by dark brown pigmentation on both the thoracic and abdominal sterna, or on the thoracic and basal abdominal sterna, or only on the thoracic sterna of the pupae.

\subsubsection{Aphytis lingnanensis Compere (lingnanensis Group)}

A. lingnanensis is characterized by dark brown pigmentation on both the thoracic and abdominal sterna of the pupa, with pupal development lasting 6 days (Figure 5). 


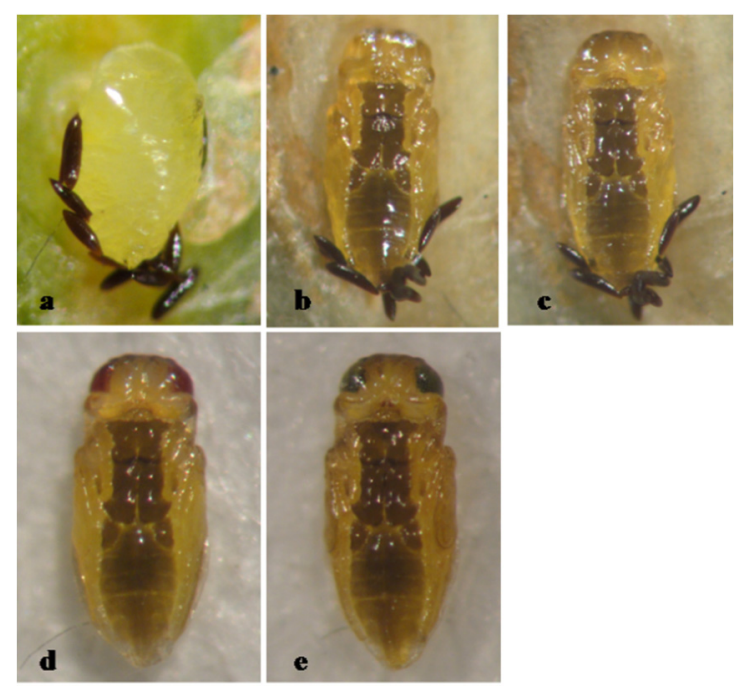

Figure 5. Aphytis lingnanensis Compere. (a) prepupa and meconia, @pupa, ventral view: (b) 1-day old, (c) 2-day old, (d) 4-day old, and (e) 6-day old (mature).

Material examined. 2ㅇ, ex Aonidiella orientalis (Newstead) on Cycas revoluta Thunb. China: Fujian, Fuzhou, Jinshan, FAFU, 15, 23.xii.2014, coll. Zhengli Zhang; 2ᄋ10, ex Pseudaonidia trilobitiformis (Green) on Ficus microcarpa L. cv. Golden Leaves, China: Fujian, Fuzhou, Jinshan, FAFU, 19.vi.2015, coll. Yu Si and Zhongchun Wen; 107, ex Pinnaspis theae on tea, China: Fujian, Fuzhou, Jinshan, FAFU, 10.vi.2015, coll. Zhongchun Wen; 10', ex Pseudaulacaspis cockerelli (Cooley) on Michelia figo (Lour.) Spreng. China: Fujian, Fuzhou, 19.vi.2015, coll. Yu Si; 2o107, ex Chrysomphalus aonidum (L.) on banana, China: Fujian, Fuzhou, Jinshan, FAFU, 22.iv.2015, coll. Yu Si; 10', ex Chrysomphalus aonidum (L.) on Ficus microcarpa L. China: Fujian, Fuzhou, Jinshan, FAFU, 10.xi.2014, coll. Xiurong Peng.

\subsubsection{Aphytis holoxanthus DeBach (lingnanensis Group)}

A. holoxanthus is characterized by dark brown pigmentationon on the thoracic and basal abdominal sterna of the pupa, with pupal development lasting 6 days (Figure 6).

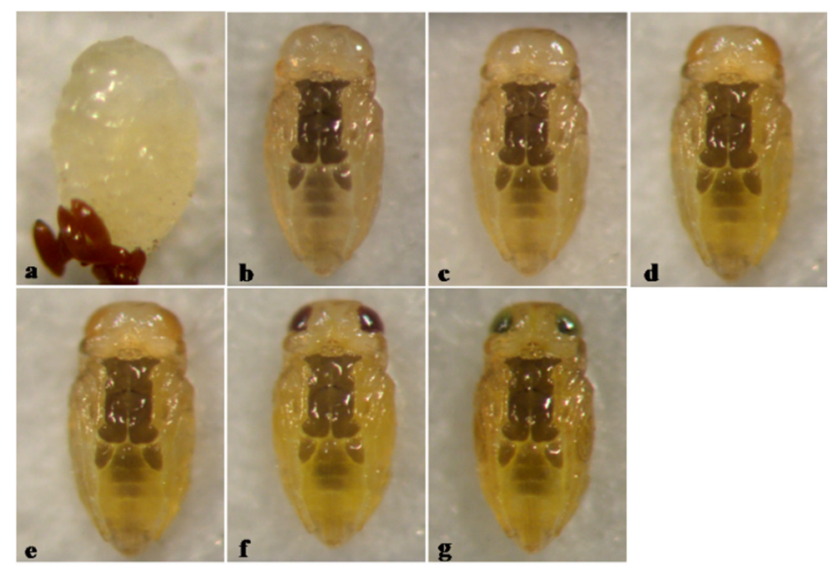

Figure 6. Aphytis holoxanthus DeBach. (a) prepupa and meconia, +pupa, ventral view: (b) 1-day old, (c) 2-day old, (d) 3-day old, (e) 4-day old, (f) 5-day old, and (g) 6-day old (mature).

Material examined. 11930", ex Chrysomphalus aonidum (L.) on Citrus maxima (Burm.) Merr. China: Fujian, Fuzhou, Pudang, 27.iii.2015, coll. Jian Huang and Zhengli Zhang; 2o, ex Pseudaulacaspis cockerelli (Cooley) on Michelia figo (Lour.) Spreng. China: Fujian, Fuzhou, 10.vi.2015, coll. Zhongchun Wen; 2\%20", ex Chrysomphalus aonidum (L.) on Osmanthus fragrans (Thunb.) Lour. China: Fujian, Fuzhou, Jinshan, FAFU, 10.v.2015, coll. Zhengli Zhang; 1920', ex Chrysomphalus aonidum (L.) on citrus, China: Fujian, Xiamen, Tong'an, 


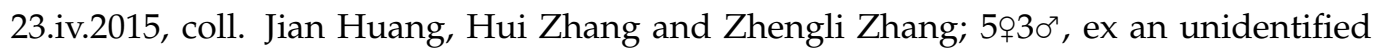
diaspidid on Nerium indicum Mill. China: Fujian, Fuzhou, 10.ix.2015, coll. Yu Si and Zhongchun Wen.

\subsubsection{Aphytis melinus DeBach (lingnanensis Group)}

A. melinus is characterized by dark brown pigmentation only on the thoracic sterna of the pupa, with pupal development lasting 6 days (Figure 7).

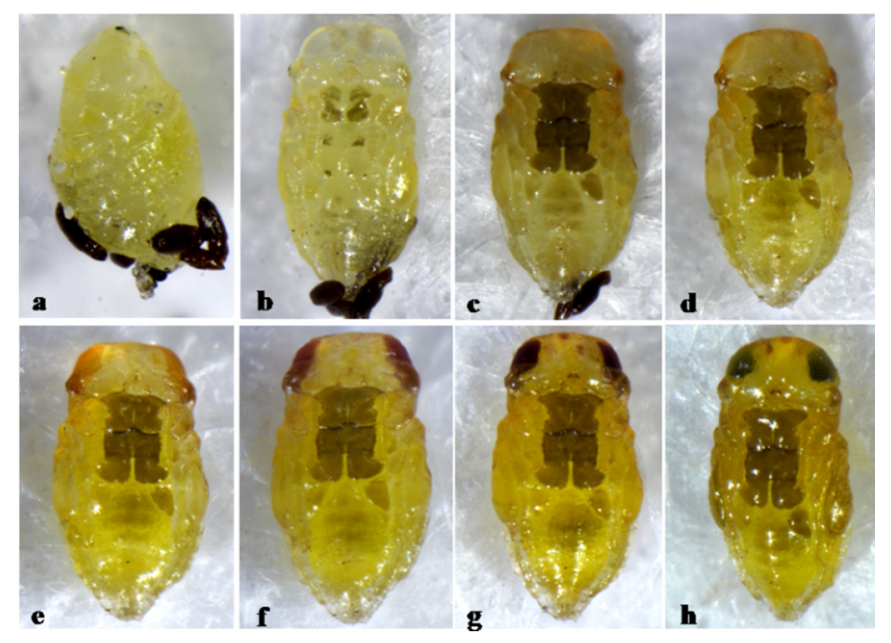

Figure 7. Aphytis melinus DeBach. (a) prepupa and meconia. \$pupa, ventral view: (b) 1-day old, (c) 2-day old, (d) 3-day old, (e) 4-day old, (f) 5-day old, (g) 6-day old, and (h) 7-day old (mature).

Material examined. 19, ex Chrysomphalus aonidum (L.) on Ficus microcarpa. China: Fujian, Fuzhou, Jinshan, FAFU, 16.i.2018, coll. Junhui Zhou; 4우, ex an unidentified diaspidid on Dianella ensifolia (L.) DC. China: Fujian, Fuzhou, Jinshan, FAFU, 4.xii.2015, coll. Zhongchun Wen; $10^{7}$, ex an unidentified diaspidid on Ficus microcarpa L. China: Fujian, Fuzhou, Jinshan, FAFU, 23.xii.2014, coll. Zhengli Zhang; 19, ex Chrysomphalus aonidum (L.) on Ficus microcarpa L. China: Fujian, Fuzhou, 26.xii.2017, coll. Yu Si; 1의, ex an unidentified diaspidid on citrus, China: Fujian, Jian'ou, 4.xi.2015, coll. Xu Cai; 19, ex Chrysomphalus aonidum (L.) on citrus, China: Fujian, Fuzhou, Minhou, 3.i.2018, coll. Yu Si and Junhui Zhou; 11ㅜㄱ, ex Chrysomphalus aonidum (L.) on Murraya exotica L. China: Fujian, Fuzhou, Jinshan, FAFU, 4.ii.2015, coll. Xiurong Peng; 10", ex Chrysomphalus aonidum (L.) on Ficus microcarpa L. China: Fujian, Fuzhou, Jinshan, FAFU, 19.vi.2015, coll. Yu Si and Zhongchun Wen.

\subsection{Type 3, Entirely or Predominantly Black Pupa}

3.3.1. Aphytis longicaudus Rosen \& DeBach (Unassigned Species)

The pupa of $A$. longicaudus is entirely black, with pupal development lasting 8 days (Figure 8).
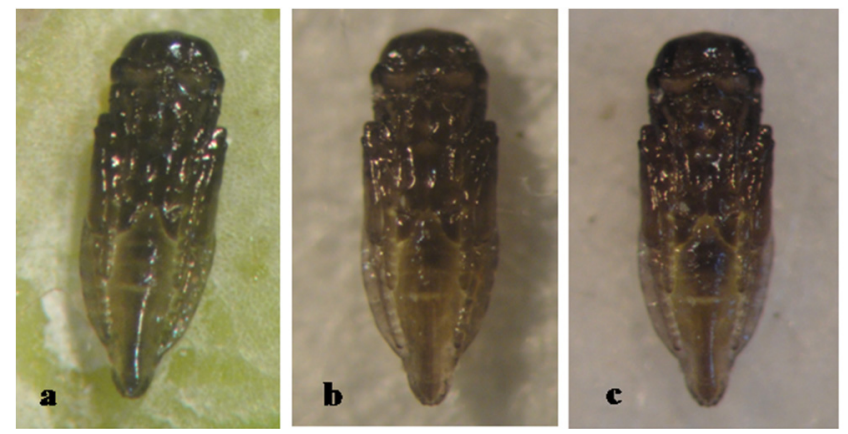

Figure 8. Aphytis longicaudus Rosen \& DeBach. @pupa, ventral view: (a) 1-day old, (b) 2-day old, and (c) 8-day (mature). 
Material examined. 1910", ex Pseudaonidia trilobitiformis (Green) on Psidium guajava L. China: Fujian, Fuzhou, Jinshan, FAFU, 3, 23.i.2015, coll. Zhengli Zhang; 3, ex Pseudaonidia trilobitiformis (Green) on Citrus maxima (Burm) Merr. China: Yunnan, Jinghong, 22.xi.2017, coll. Jian Huang and Zhuhong Wang; 4의 ex Pseudaonidia trilobitiformis (Green) on tree, China: Fujian, Jiangle, ix.2011, Lianbin Ye.

3.3.2. Aphytis sankarani Rosen \& DeBach (Species Group Placement Intermediate between lingnanensis and mytilaspidis Groups)

The pupa of $A$. sankarani is predominantly black, except for being pale on the distad abdominal sterna, with pupal development lasting 6 days (Figure 9).

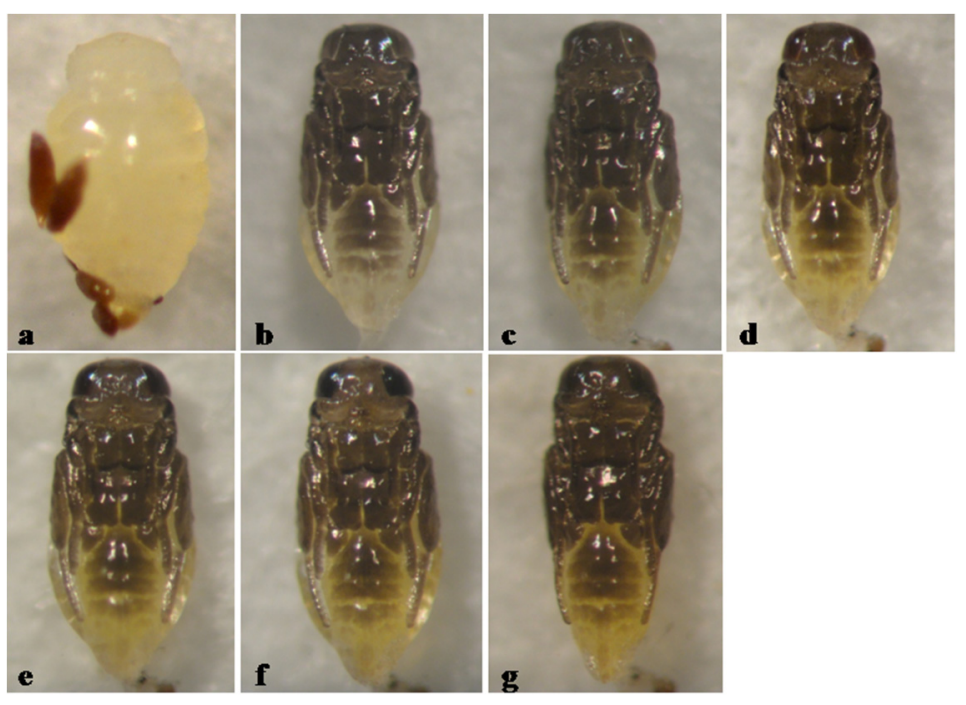

Figure 9. Aphytis sankarani Rosen \& DeBach. (a) prepupa and meconia, \$pupa, ventral view: (b) 1-day old, (c) 2-day old, (d) 3-day old, (e) 4-day old, (f) 5-day old, and (g) 6-day old (mature).

Material examined. 2o, ex Pseudaulacaspis cockerelli (Cooley) on Excoecaria cochinchinensis Lour. China: Fujian, Fuzhou, Jinshan, FAFU, 10.ii.2015, coll. Hui Zhang; 3o10', ex Pseudaulacaspis cockerelli (Cooley) on Michelia figo (Lour.) Spreng. China: Fujian, Fuzhou, Jinshan, FAFU, 14.xii.2014, coll. Xiurong Peng; 10960', ex Pseudaulacaspis cockerelli (Cooley) on Michelia figo (Lour.) Spreng. China: Fujian, Fuzhou, Jinshan, FAFU, 6.iv.2015, coll. Yu Si and Zhongchun Wen; 44ㅇ', ex Pseudaulacaspis cockerelli (Cooley) on Michelia figo (Lour.) Spreng. China: Fujian, Fuzhou, Jinshan, FAFU, 16.vi.2015, coll. Zhongchun Wen.

\subsection{Type 4, Partly Black Pupa}

Aphytis sp. (Unassigned Species)

The pupa of Aphytis sp. is partly black except for yellow on the abdominal sterna, with pupal development lasting 6 days (Figure 10).

Material examined. 3q, ex an unidentified diaspidid on Citrus maxima (Burm.) Merr. China: Fujian, Fuzhou, Jinshan, FAFU, 10.xii.2017, coll. Yu Si and Junhui Zhou; 53o', ex Parlatoria zizyphus (Lucas) on citrus, China: Fujian, Fuzhou, Jinshan, FAFU, 9.vii.2018, coll. Yu Si and Junhui Zhou. 


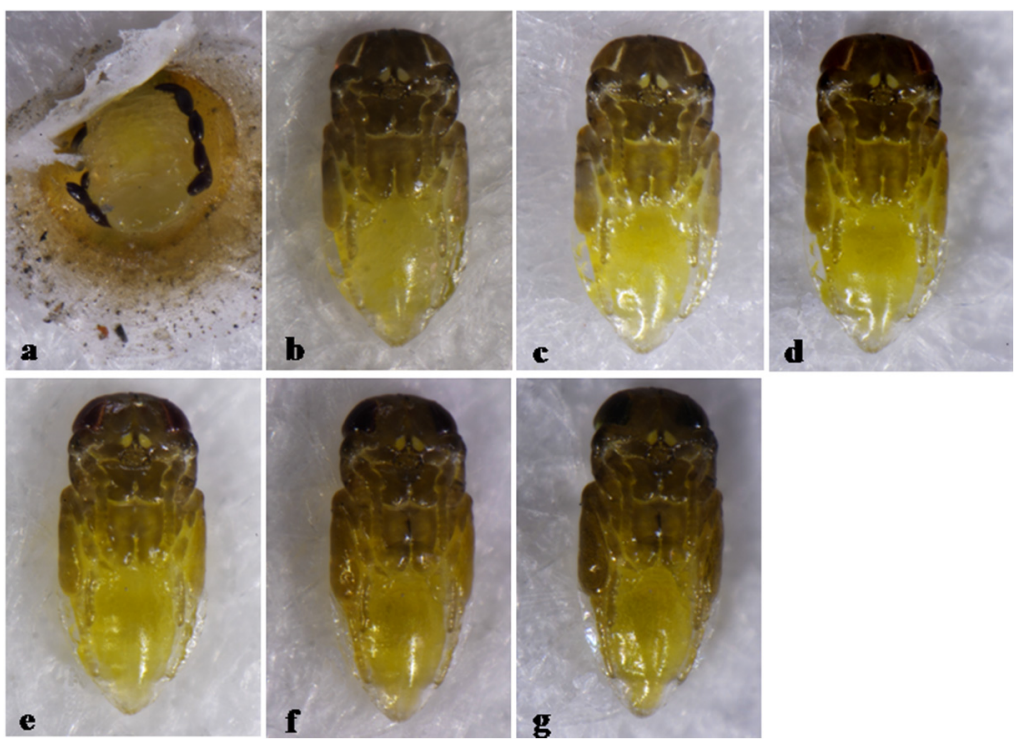

Figure 10. Aphytis sp. (a) prepupa and meconia on the scale, opupa, ventral view: (b) 1-day old, (c)2-day old, (d) 3-day old, (e) 4-day old, (f) 5-day old, and (g) 6-day old (mature).

\subsection{Pupal Development}

The pupae of Aphytis species in this study had a developmental duration of about 5-8 days at $27 \pm 1{ }^{\circ} \mathrm{C}, 70 \pm 5 \% \mathrm{RH}$ and a photoperiod of 10L: 14D. The experiments showed that the pupal skin was always melanized at beginning stage, generally in the first day, among the pigmented pupae of Aphytis species. As development continued, the pigmentation became darker and the eye colour from pale red/brown to green/black brown.

\section{Discussion}

Until now less than one-third of the known species of Aphytis have had their pupal pigmentation described (Table 1).

Table 1. The present status of pupal pigmentation described in the known species of Aphytis ${ }^{(1)}$.

\begin{tabular}{|c|c|c|c|c|}
\hline Sp. Group & No. of sp. + Related sp. & $\begin{array}{l}\text { No. of sp. Recorded with } \\
\text { Pupal Pigmentation }\end{array}$ & Type of Pupal Pigmentation & References \\
\hline chilensis & $5+2$ & 2 & \multirow{8}{*}{$\begin{array}{l}\text { entirely or partly black } \\
\text { entirely yellow, or some with } \\
\text { brownish appendages } \\
\text { entirely yellow } \\
\text { partly dark brown; } \\
\text { entirely yellow } \\
\text { entirely or predominantly black } \\
\text { generally entirely yellow (2) } \\
\text { entirely or predominantly } \\
\text { black }\end{array}$} & {$[1,16]$} \\
\hline chrysomphali & 17 & 5 & & {$[1,3,16-19]$} \\
\hline funicularis & 5 & 2 & & {$[1,20]$} \\
\hline lingnanensis & 19 & 11 & & {$[1,3,9,17,19,21-25]$} \\
\hline mytilaspidis & $8+5$ & 5 & & {$[1,26]$} \\
\hline proclia & $13+6$ & & & {$[1,27-29]$} \\
\hline unassigned sp. & 15 & 3 & & {$[1,27,28,30,31]$} \\
\hline Total sp. ${ }^{(3)}$ & 95 & 28 & & \\
\hline
\end{tabular}

Notes: ${ }^{(1)}$ According to the record by Rosen and DeBach [1] and the authors following them. (2) Summary comment on the pupal pigmentation of proclia group by Rosen and DeBach [1]. ${ }^{(3)}$ The 27 species in the vittatus group of Aphytis were transferred to the genus Paraphytis [32].

Of the known species of Aphytis (Table 1), the species in the chilensis and mytilaspidis groups, and some unassigned species, generally have entirely, or predominantly and or partly black pupae.

The species in the chrysomphali, funicularis, and proclia groups generally have the pupae entirely yellow. However, the pupal pigmentation of the proclia group seems to be generally mottled with fuscous; wing pads and appendages appear fuscous to black; 
dark areas or furcae are visible on both dorsal and ventral surfaces of mesosoma and metasoma; metasomal segments with dark patches dorso-laterally. Actually the pupal skin itself is usually not melanized at all. It is straw-yellow, and the melanization seen is that of the developing adult. Coarse, black spines are also usually evident through the integument of the fully developed pupa $[1,8,9]$. By comparison, the pupal skins of other types are melanized.

The species of the lingnanensis group have the pupae entirely yellow, e.g., A. fisheri, and partly dark brown pupae, e.g., A. lingnanensis, A. holoxanthus and A. melinus, which are almost inseparable by adult characters, but their differences in pupal pigmentation provides a method to separate these species.

\section{Conclusions}

This study summarized four characteristic pigmentation patterns of Aphytis pupae, including entirely yellow, partly dark brown, entirely or predominantly black, and partly black. No significant intra-specific variation in pupal colour pattern was detected despite relatively high numbers of specimens examined, many from multiple, and different, origins. Although one type of pupal pigmentation is shared with more than one species group, and pupal pigmentation is somewhat variable at times, for example the new pigmentation patterns were reported in some individuals of $A$. melinus and $A$. chrysomphali species respectively [33], the pupal pigmentation certainly may be regarded as an important supplementary diagnostic character, based on the morphological characters, and may even serve as a convenient shortcut to the separation of certain closely related species of Aphytis.

Author Contributions: Z.W. and J.H. conceived the study research. Y.S., H.Z., Z.Z. and J.H. collected samples and conducted some labwork. J.H. and Z.W. conducted some labwork and analyzed the data. Z.W. and J.H. wrote the manuscript. A.P. edited the manuscript. All authors have read and agreed to the published version of the manuscript.

Funding: This study was funded by National Key R \& D Program of China (2017YFD0201000, 2017YFE0104900).

Institutional Review Board Statement: Not applicable.

Data Availability Statement: Data are contained within the article.

Acknowledgments: We are grateful to the students Xiurong Peng, Zhongchun Wen and Junhui Zhou in our research team (Fujian Agriculture and Forestry University, China) for collecting of the materials. We would also like to thank three anonymous reviewers for their helpful comments on a previous version of this paper.

Conflicts of Interest: The authors declare no conflict of interest.

\section{References}

1. Rosen, D.; DeBach, P. Species of Aphytis of the World; Springer: Amsterdam, The Netherlands, 1979.

2. Rosen, D. Parasitic Hymenoptera in biological control: The genus Aphytis. In Advances in Parasitic Hymenoptera Research; Gupta, V., Ed.; EJBrill: Leiden, The Netherlands; New York, NY, USA, 1988; pp. 411-416.

3. Huang, J. Systematic Studies on Aphelinidae of China (Hymenoptera: Chalcidoidea); Chongqing Publishing House: Chongqing, China, 1994.

4. Noyes, J. Collecting and preserving chalcid wasps (Hymenoptera: Chalcidoidea). Ann. Mag. Nat. Hist. 1982, 16, 315-334. [CrossRef]

5. Taylor, T.H.C. The Campaign against Aspidiotus destructor, Sign., in Fiji. Bull. Entomol. Res. 1935, 26, 1. [CrossRef]

6. Flanders, S.E. Aphelinid biologies with implications for taxonomy. Ann. Entomol. Soc. Am. 1953, 46, 84-94. [CrossRef]

7. Compere, H. A Systematic Study of the Genus Aphytis Howard (Hymenoptera, Aphelinidae) with Descriptions of New Species; University of California Press: Berkeley, CA, USA, 1955; pp. 277-321.

8. DeBach, P. New species and strains of Aphytis (Hymenoptera, Eulophidae) parasitic on the California red scale, Aonidiella Aurantii (Mask.), in the Orient. Ann. Entomol. Soc. Am. 1959, 52, 354-362. [CrossRef]

9. DeBach, P. Aphytis riyadhi n. sp. (Hymenoptera: Aphelinidae), a parasite of Aonidiella spp. (Homoptera: Diaspididae). Entomophaga 1979, 131-138. 
10. Quednau, F.W. A contribution on the genus Aphytis Howard in South Africa. (Hymenoptera: Aphelinidae). J. Entomol. Soc. S. Afr. 1964, 27, 86-116.

11. Rosen, D.; DeBach, P. Systematics, morphology and biological control. Entomophaga 1973, 18, 215-222. [CrossRef]

12. Bedford, E.C.G. Red scale, Aonidiella aurantii (Mask.). In Citrus Pests in the Republic of South Africa; Bedford, E.C.G., Ed.; Department of Agricultural Technical Services, Republic of South Africa, Science Bulletin; The Government Printer: Pretoria, South Africa, 1978; Volume 391, pp. 109-118.

13. Yasnosh, V.A. A contribution to biosystematic description of species of the genus Aphytis Howard (Chalcidoidea, Aphelinidae) which are parasites of scale insects in the USSR. Entomol. Rev. 1972, 51, 146-152.

14. Prinsloo, G.L. An illustrated guide to the parasitic wasps associated with citrus pests in the Republic of South Africa. Repub. S. Afr. Dep. Agric. Sci. Bull. 1984, 402, 1-119.

15. Huang, J. Notes on Aphytis holoxanthus DeBach (Hymenoptera: Aphelinidae), a parasite of the Florida red scale, Chrysomphalus aonidum (L.) (Homoptera: Diaspididae). J. Fujian Agric. Coll. 1989, 18, 403-408.

16. Prinsloo, G.L.; Neser, O.C. The Aphytis fauna of the Afrotropical region. In Advances in the Study of Aphytis (Hymenoptera: Aphelinidae); Rosen, D., Ed.; Intercept Ltd.: Andover, UK, 1994; pp. 295-298.

17. Ren, H. Two new species of Aphytis from China (Hymenoptera, Aphelinidae). Entomotaxonomia 1988, 10, $220-221$.

18. Rosen, D.; Rose, M. Aphytis fioriniae, sp. nov. (Hymenoptera: Aphelinidae), a parasite of tea scale, Fiorinia theae Green, from India. Orient. Insects 1989, 23, 269-273. [CrossRef]

19. Abd-Rabou, S. Revision of the genus Aphytis (hymenoptera: Aphelinidae) with descriptions of two new species from Egypt. Insect Sci. 2008, 11, 149-164. [CrossRef]

20. Rose, M.; Rosen, D. A new species of Aphytis (Hymenoptera: Aphelinidae) parasitic upon the arrow-head scale, Unaspis yanonensis (kuwana), from the people's republic of China. Entomotaxonomia 1991, 2, 120-123.

21. DeBach, P. Aphytis simmondsiae n. sp. (Hymenoptera: Aphelinidae), a parasite of jojoba scale, Diaspis simmondsiae (Homoptera: Diaspididae). Folia Entomol. Mex. 1984, 60, 104-114.

22. DeBach, P.; Rosen, D. Aphytis yanonensis n. sp. (Hymenoptera, Aphelinidae), a parasite of Unaspis yanonensis (Kuwana) (Homoptera, Diaspididae). Jpn. J. Entomol. 1982, 50, 626-634.

23. Abdrabou, S. The holotype deposition of Aphytis sinaii Abd-Rabou (Hymenoptera: Aphelinidae), an external parasitoid of the California red scale, Aonidiella aurantii (Maskell). Egypt. J. Biol. Pest Control 2005, 15, 159.

24. Li, C.; Yang, Q. A systematic study on the genus Aphytis Howard (Hymenoptera:Aphelinidae) from South Korea. Entomotaxonomia 2004, 26, 307-312.

25. Hanan, R.M.; Hedaya, K.H. Aphytis alexandrina (Hymenoptera: Chalcidoidea: Aphelinidae) a new species from Alexandria, Egypt. Egypt. J. Entomol. 2013, 10, 49-52. [CrossRef]

26. Li, C. Two new species of Aphelinidae (Hymenoptera: Chalcidoidea) from northeastern region of China. J. North-East For. Univ. 1996, 24, 98-101.

27. Rosen, D.; DeBach, P. Three new species of Aphytis (Hymenoptera: Aphelinidae), parasites of Pseudaulacaspis spp. (Homoptera: Diaspididae) in India and Australia. Entomophaga 1986, 31, 139-151. [CrossRef]

28. Hayat, M. Aphelinidae of India (Hymenoptera: Chalcidoidea): A Taxonomic Revision; Associated Publishers: Gainesville, FL, USA, 1998.

29. Hayat, M.; Veenakumari, K.A. Aphelinidae (Hymenoptera: Chalcidoidea) from Andaman \& Nicobar Islands. J. Insect Syst. 2015, $1,92-106$.

30. Myartseva, S.N.; Ruíz-Cancino, E.; Coronado-Blanco, J.M. El género Aphytis Howard (Hymenoptera: Chalcidoidea: Aphelinidae) en México, clave de especies y descripción de una especie nueva. Dugesiana 2010, 17, 81-94.

31. Yasnosh, V.A. Aphytis species occurring in the former USSR and their role in biological control. In Advances in the Study of Aphytis (Hymenoptera: Aphelinidae); Rosen, D., Ed.; Intercept Ltd.: Andover, UK, 1994; pp. 317-333.

32. Noyes, J. Universal Chalcidoidea Database. Available online: http://www.nhm.ac.uk/chalcidoids (accessed on 16 October 2020).

33. Pina, T.; Verdú, M.; Urbaneja, A.; Sabater-Muñoz, B. The use of integrative taxonomy in determining species limits in the convergent pupa coloration pattern of Aphytis species. Biol. Control 2012, 61, 64-70. [CrossRef] 